\title{
The Mandate of Scholarly Mathematics Education Research: Moving Ourselves Forward
}

\author{
Ann Kajander (i)
}

Accepted: 10 December 2020 / Published online: 7 January 2021

(C) Ontario Institute for Studies in Education (OISE) 2021

\begin{abstract}
The 20th anniversary of this journal finds us at a crossroads in many ways. Mathematics education itself has always existed at an unclear intersection of mathematics and education. As well, in mathematics education, the poles of reform and traditional learning can pull the community apart. And now, in the world, we find ourselves at a crossroads in terms of priorities related to the future of the planet. In this article, I reflect on past work, and theorise about the future role of mathematics education research, given these new realities, in moving forward.
\end{abstract}

Résumé Le $20^{\mathrm{e}}$ anniversaire de cette revue nous place à la croisée des chemins à bien des égards. L'enseignement des mathématiques lui-même s'est toujours trouvé à une intersection peu claire des mathématiques et de l'éducation. De plus, dans l'enseignement des mathématiques, les pôles de la réforme et de l'apprentissage traditionnel peuvent diviser la communauté. Et maintenant, dans le monde, nous nous trouvons à la croisée des chemins en ce qui a trait aux priorités liées à l'avenir de la planète. Dans cet article, je réfléchis aux travaux antérieurs et je théorise sur le rôle futur de la recherche en enseignement des mathématique, compte tenu de ces nouvelles réalités, pour aller de l'avant.

Keywords Mathematics education · Attitudes to mathematics $\cdot$ Mathematics in the media

\section{Introduction}

Many years ago, I attended a working group called Mathematics Education, Society, and Peace at the Canadian Mathematics Education Study Group Conference (Powell \& Dawson, 2005). As we initially introduced ourselves around the room, we were asked to reflect on our perception of the experience and purpose of learning mathematics, as well as our own personal purpose for doing so. At least one mathematician in the group shared their enjoyment of doing mathematics as a kind of escape, a mental refuge from the woes of the world. In stark contrast, a young and clearly passionate participant somewhat shocked the group by suggesting that, in his view, the purpose of mathematical learning should not be to escape the world, but rather to improve it, and that morally, we as mathematics educators should collectively

A. Kajander $(\bowtie)$

Mathematics Education, Lakehead University, 955 Oliver Road, Thunder Bay, ON, Canada

e-mail: ann.kajander@lakeheadu.ca 
believe in and share that mandate. I refer of course to the now well-known and influential teacher and author David Stocker, who was then just finishing his first book Maththatmatters (Stocker, 2007). This book contains classroom lessons in mathematics that support social justice themes. Any possible comfortable disengagement from the "real" world was suddenly disrupted by David's suggestion.

During my own early days as a researcher and writer, I often felt the tension between "pure" research, that is, research done for its own sake, and research conducted for the specific purpose, at least secondarily, of making classrooms better places. I remember being somewhat disappointed to find that this latter goal did not at all seem to be an important one for publishing scholarly articles in mathematics education, and this situation always bothered me to at least some extent. As Canada's own "Leonardo DaVinci" visionary mathematician and mathematics educator Peter Taylor would say, "what's it all for"?

On reflecting on writing for the 20th Anniversary Issue of this journal, and invited to think about the future of our discipline, I found myself squarely back, facing my conflicted thoughts of 20 years ago. I found myself asking ... Why are we doing this scholarly work? And what is writing about it all for?

Enter the pandemic, and the connected threads of environmental concerns. I have found myself, during the pandemic, thinking more and more about the moral imperative of mathematics education. What, if any, is our obligation as mathematics education researchers? Branching off for a moment to contemplate the fate of our planet and environment, we know that, to a large extent, the science is there, and the data are there. But to make predictions about what is going to happen next, based on what has been observed and measured so far, we need mathematics. And that particular mathematics needed is not standard techniques such as factoring or differentiating - rather, it is everything the research says is needed to make mathematics classrooms more effective, such as modeling and reasoning. Predicting a pandemic or climate change, based only on the data collected to date, is inherently a mathematics problem. I asked myself, does this change anything? I believe it does.

In parallel, mathematics educators are often ostensibly bothered by the very bad reputation that both mathematics as a discipline, as well as the teaching of mathematics, seem to have in the public eye and media (Holm \& Kajander, 2019). I am sure we have all experienced talking to someone socially and reluctantly admitting to what we do for a living - only to find the other person, valiantly trying to cover their distaste, involuntarily taking a step back! But our concern about that response tends to be non-participatory. Within our own groups of mathematics educators, we shake our heads and say this is "unfortunate", and that people "don't understand", but secretly, we feel it is really not up to us to change the situation of the frequently poor public view of mathematics. Perhaps we are even doing work in a classroom, and so we feel we are doing our part. Except - typically — this means we are doing work in one classroom out of the hundreds around us. It's just not enough to change perceptions. But after all, we justify, is it not really up to the profession, and to articles written in professional journals, to translate our scholarly work into something useful for classrooms more generally?

I have come to feel, more and more emphatically, that the answer to that question is "no". We, as mathematics education researchers, scholars, and authors, can no longer afford to remain in the safe and lofty refuge of academia, with insufficient regard to improving classroom learning of mathematics, changing public perceptions, and ultimately, doing our part to improve the world.

What then should our new role be? And what can we, as mathematics educators, actually do that might help students learn to reason mathematically? Suppose we were to believe, as I imagine most of us do, that mathematics is a tool with which to think, reason, and make good decisions, including those about the real world. And suppose too, that if more people had this type of mathematical capacity, that we might be better equipped to deal with the world's challenges. Our role, then, both in research and teaching, fundamentally becomes one of equipping teachers to support this type of classroom learning - specifically in order to help their students develop the capacity to reason and make good decisions. While thinking about this paradigm shift is not new, neither has it been universally achieved. It is even still socially acceptable to be "not a math person".

Ultimately, I have found over and over again that people's perceptions of mathematics - and their own capacity with it — change fundamentally when they experience what it feels like to really understand it. I do not mean that they can factor quadratic expressions. I mean that they can reason about it. That they can look at a 
graph such as the one below (reconstructed from a recent periodical article about COVID-19 infections in a region of North America), and realise that the arrow is at best, not very helpful, and at worst, misleading (Fig. 1).

In the original graph, the arrow was shown in a bold red. Pulling out my ruler, I noted that, while there was no doubt some time period with such a slope, neither of the logical ones (the vertex to the present week, or the last few weeks) were represented by the arrow. Yet, the red arrow was highly compelling. Understanding of rates of change remains a significant challenge, as has been noted in the past (Kajander \& Lovric, 2009). People may be able to compute, or use tools such as graphing software, but can they reason?

We have also been invited to reflect on our own publications within the Canadian Journal of Mathematics, Science, and Technology Education. In what I believe represents our most downloaded article, (Holm \& Kajander, 2012), Jennifer Holm and I argue for the need for beliefs and values about mathematics and mathematics learning to be fundamental to the benefit of any parallel learning of mathematical ideas. In fact, we have not observed preservice elementary teachers to have unfounded emotions about mathematics when entering the program and specifically mathematics-for-teachers courses; rather, their fears are rational responses to a known state. They do not deeply understand mathematical concepts, and they are well aware of this (Kajander, 2010). This is certainly not an irrational sort of "anxiety", to be alleviated by comforting words and calm surroundings. Rather, the best medicine — and one which works with surprising speed — is to support their experiencing immediate success in the development of their mathematical understanding and capacity (Kajander, 2010; Kajander \& Holm, 2016).

Prospective secondary mathematics teachers, on the other hand, may be surprised at how superficial their mathematical understanding really is (Holm \& Kajander, 2020), and may also need to deepen their fundamental understandings. Colleague Miroslav Lovric and I have also argued that resources teachers rely on, such as textbooks and curriculum documents, need to better support such fundamental understandings (e.g. Kajander \& Lovric, 2018).

I believe that we, as the Canadian mathematics education community, need to fundamentally shift our purpose. We need to actively develop ourselves as outspoken advocates of the need to think and reason, and explain that this capacity is what mathematics is. Wolfram (2010) goes as far as to suggest that, if a computer can do a certain mathematical process, it is not important enough for students to spend a lot of time on.

We need to be at least as active in the media as people who are ill-informed about mathematical thinking, learning, and reasoning. No excuses. Canada is home to a number of vocal individuals who deeply believe that "the fundamentals" are the most important part of what is needed. We need to match that empathic, vocal messaging - with more informed and helpful ones. If the public only hears from those who think "doing the math" means learning procedures, and that students just need "the fundamentals", we have only ourselves to blame. We must all become vocal advocates for thinking, reasoning, good decision-making, and ultimately the future of the planet.

Unfortunately, such advocacy seems to invite, at times, rather personal and aggressive rebuttals. For example, recently Jennifer Holm and I wrote a commentary in The Conversation, (Holm \& Kajander, 2019), an online educational forum, about the Ontario mathematics curriculum. While I knew that some high profile mathematics educators have endured harsh criticism in the past, I was not quite prepared for some of the comments. For example, the online comments included:

- It's lovely for ed[ucation] faculty to churn out this stuff but they're not the ones dealing with sobbing children at the dining table

- I smell the influence of Jo Boaler here

- Are these 2 professors, "math professors", i.e. have a background/degree in mathematics, or "math education professors" which [sic] have a background in education? Clarifying this specific point is crucial to the legitimacy of the content of the article. Why? Because most of the damage inflicted on math curricula and resources over the past 2-3 decades hails from education departments, which have been in charge of training our teachers

- Condescension ... just drips from this article 


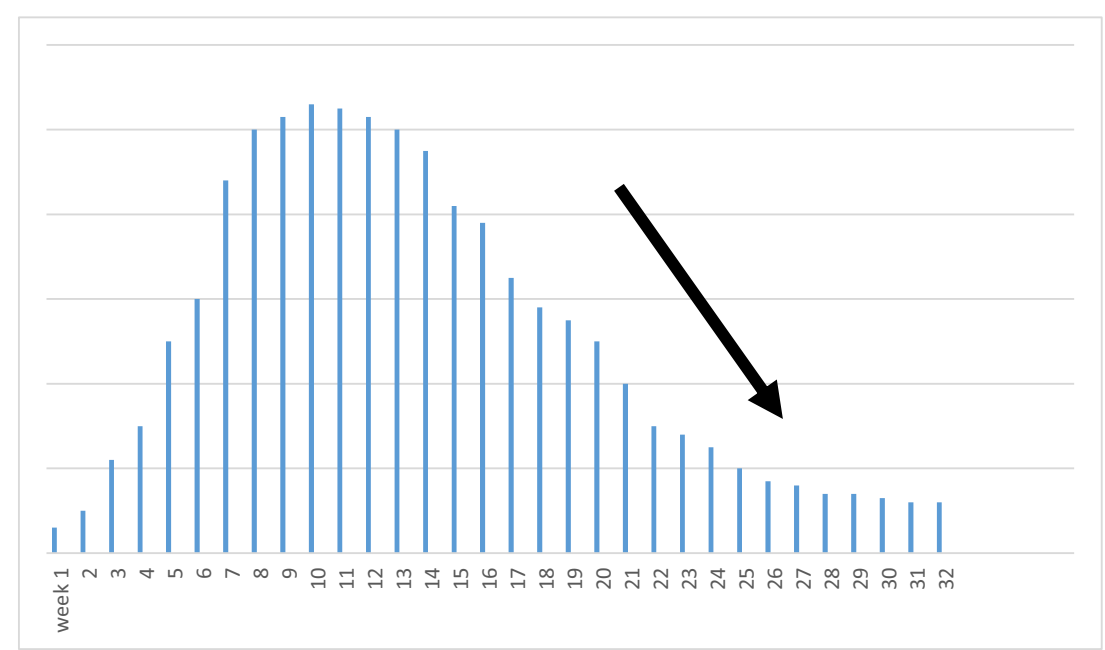

Fig. 1 Sample periodical bar graph of new pandemic infections for a given region

It is all too easy to withdraw from the public debate in response to such comments. However, we cannot. My only explanation for the depth of anger expressed about the mathematics teaching debate is that the damage inflicted by historical teaching of mathematics has left people with a very narrow vision, and somewhat scarred. Rather, we must continue to work to clarify, explain, and advocate. In particular, we need to energetically stand up for one another. We need a unified front in mathematics education, and we must publicly support one another even more vigorously than the critiques received.

I shall end with two challenges. First, let us focus our scholarly work on research that has the explicit purpose of helping students learn mathematics better, namely as a tool with which to think, reason, and make good decisions. I would like to see future articles that have the possibility of helping to support continued improvement in the quality of mathematics classroom learning prioritized in the Canadian Journal of Science, Mathematics and Technology Education. Second, let us become more vocal in our public advocacy for mathematics education, whether or not that is within our comfort zone. When we read such an article posted by a colleague, we need to be outspoken in our support of it, rather than letting the critiques take over the commentary, as happened after the Conversation article (Holm \& Kajander, 2019). Let us provide and vigorously work to share and populate good (and not excessively difficult to understand) examples of what it means to think and reason mathematically, and why such learning is crucially important. And now, along with our next submission to the Canadian Journal of Science, Mathematics and Technology Education, shall we each write an article for our favourite online site or local newspaper?

\section{Compliance with Ethical Standards}

Conflict of Interest The author declares that there is no conflict of interest.

\section{References}

Holm, J. \& Kajander, A. (2012). Interconnections of knowledge and beliefs in teaching mathematics. Canadian Journal of Science, Mathematics, and Technology Education 12(1). 7-21.

Holm, J. \& Kajander, A. (2019). Ontario math has always covered "The Basics". The Conversation. https://theconversation. com/ontario-math-has-always-covered-the-basics-115445. Accessed 5 Jan 2021.

Holm, J. \& Kajander, A. (2020). Seeking intersections: Math degrees, beliefs, and elementary teacher knowledge. Canadian Journal of Science, Mathematics, and Technology Education, 20, 27-41. https://doi.org/10.1007/s42330-019-00069-3 
Kajander, A. (2010). Teachers constructing concepts of mathematics for teaching and learning: "It's like the roots beneath the surface, not a bigger garden". Canadian Journal of Science, Mathematics, and Technology Education 10(2), 87-102.

Kajander, A., \& Holm, J. (2016). What math matters? Types of mathematics knowledge and relationships to methods course performance. Canadian Journal of Science, Mathematics, and Technology Education, 16(3), 273-283. DOI: https://doi. org/10.1080/14926156.2016.1183837

Kajander, A. \& Lovric, M. (2009). Mathematics textbooks and their potential role in supporting misconceptions. International Journal of Mathematical Education in Science and Technology, 40(2), pp. 173-181.

Kajander, A. \& Lovric, M. (2018). "It doesn't exist": Infinity and division by zero in the Ontario mathematics curriculum. Canadian Journal of Science, Mathematics, and Technology Education, 18(2), 154-163. https://doi.org/10.1007/s42330018-0013-4

Powell, A. \& Dawson, A.J. (2005). Mathematics education, society, and peace. In P. Liljedahl, Ed., The Proceedings of the 2005 Annual Meeting of the Canadian Mathematics Education Study Group. Ottawa: University of Ottawa. pp. 21-26.

Stocker, D. (2007). Maththatmatters. Canadian Centre for Policy Alternatives Education Project.

Wolfram, C. (2010). Teaching kids real math with computers. TED Global. https://www.ted.com/talks/conrad_wolfram_ teaching_kids_real_math_with_computers?language=en

Publisher's Note Springer Nature remains neutral with regard to jurisdictional claims in published maps and institutional affiliations. 